\title{
ASSETS OF MARSUPIALIZATION OVER ENUCLEATION IN THE TREATMENT OF LARGE ODONTOGENIC CYSTS: REPORT OF TWO CASES
}

Gurnam Singh, MDS, ${ }^{1}$ Dinesh Kumar, MDS, ${ }^{1}$ Swati Kapoor, MDS, ${ }^{1}$ Puneet Bajaj, MDS, ${ }^{2}$ Alka Bhardwaj, ${ }^{2}$ Manisha Bhalla, BDS ${ }^{1}$ ${ }^{1}$ Department of Oral and Maxillofacial Surgery, Bhojia Dental College and Hospital, Budh, Baddi, Himachal Pradesh, India ${ }^{2}$ Department of Oral Pathology and Microbiology, Bhojia Dental College and Hospital, Budh, Baddi, Himachal Pradesh, India

\begin{tabular}{|c|c|}
\hline $\begin{array}{r}\text { Correspondence address: } \\
\text { Dr. Dinesh } \\
\text { Department of Oral \& } \\
\text { Maxillofacial Surgery } \\
\text { Bhojia Dental College and } \\
\text { Hospital, Budh, Baddi } \\
\text { Himachal Pradesh 173205, India }\end{array}$ & 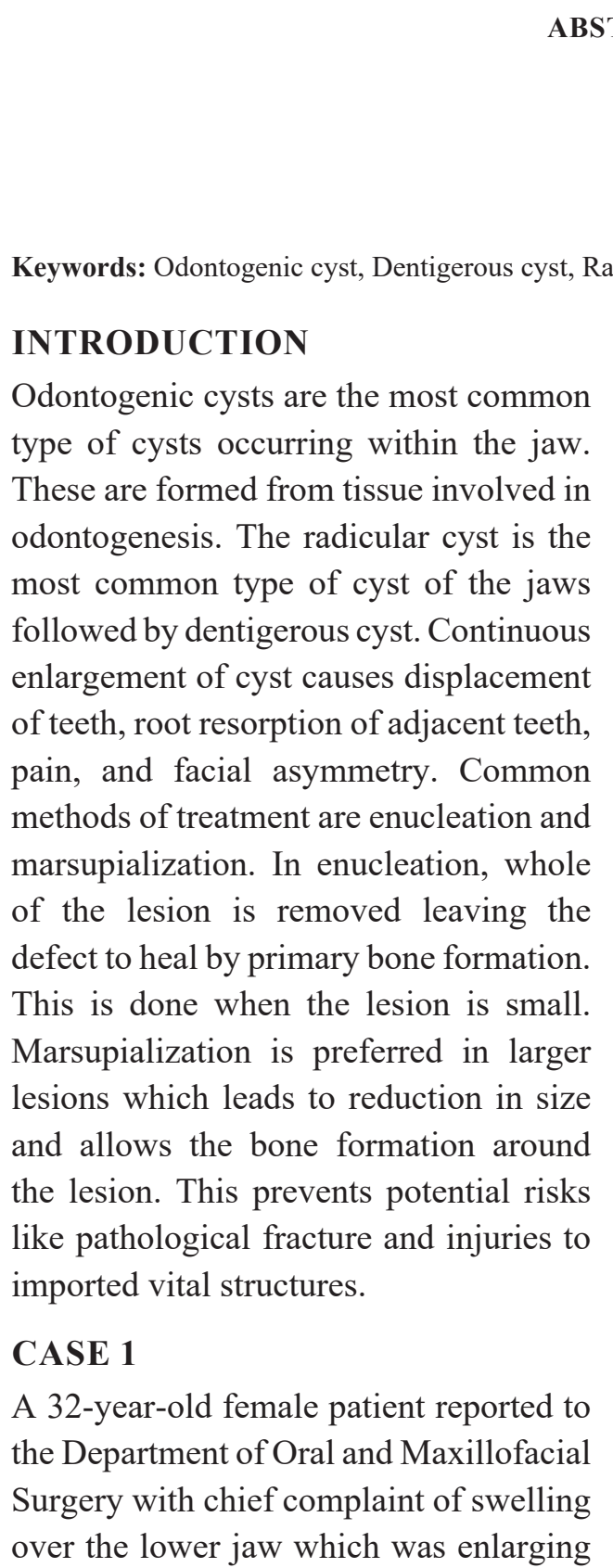 \\
\hline
\end{tabular}

slowly since last 1 year, leading to facial asymmetry (Figure 1). The patient gave a history of intermittent pain in lower teeth since more than a year, which used to subside on taking analgesics.

On general examination, the patient was healthy and there was no apparent history of past illness or hospitalization or trauma to the jaw. On extraoral examination, facial asymmetry was noted on lower third of the face, with no sinus or active discharge of pus (Figure 1).

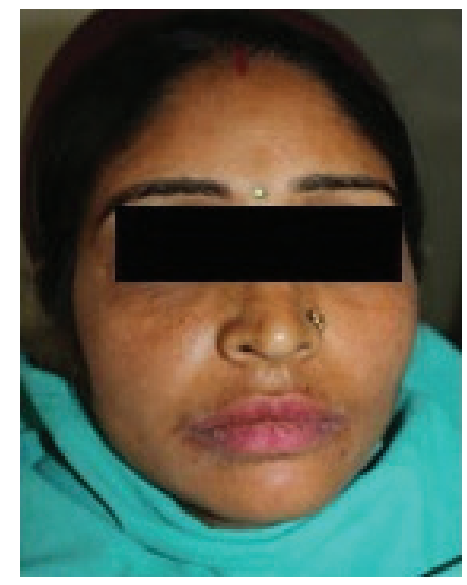

Figure 1: Clinical image of the patient showing swelling over lower third of face. 
The submandibular and submental lymph nodes were nonpalpable. On intraoral examination, a swelling in mandibular anterior teeth region was noted which was obliterating the labial vestibule. The swelling was soft and fluctuant on the labial side with a "typical egg shell crackling." Right mandibular canine was missing, while the rest of the permanent teeth were present (Figure 2).

In the Orthopantomograph, an oval-shaped, unilocular radiolucency was noticed around the crown of right impacted mandibular canine which was displaced to the lower border of the mandible. The lesion was extending from first premolar on right side to the second premolar on the opposite side weakening the cortex all around (Figure 3).

The contents of the swelling were aspirated which revealed straw colored fluid. The cytopathologic examination of the aspirate showed mucoid material,

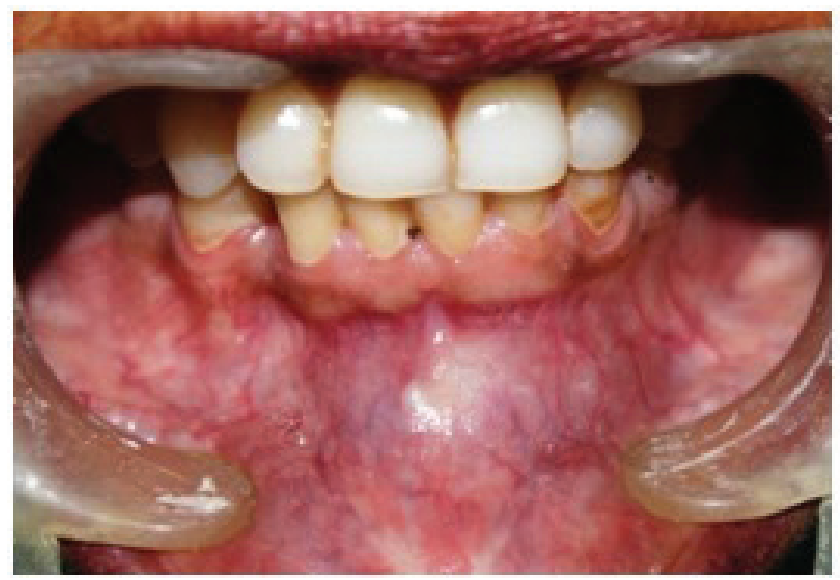

Figure 2: Intraoral image of the patient showing swelling in the labial vestibule and missing right canine.

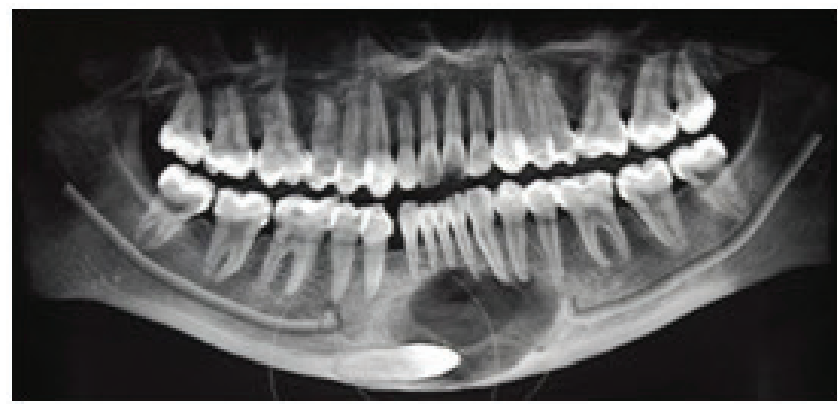

Figure 3: OPG showing large radiolucent lesion and impacted canine. red blood cell (RBC), clumps of benign epithelial cells, and plenty of cyst macrophages (Figure 4).

A provisional diagnosis of dentigerous cyst was made on the basis of history, clinical and radiological findings. Lower anterior teeth were found to be nonvital, while the involved premolars were vital when tested for vitality. As the size of the lesion was extensive, it was decided to go for computed tomographic examination which in turn confirmed the weakening of both lingual and labial cortices along with thinning of lower border of mandible (Figure 5).

For the management of the case, a preventive approach was followed as there was a real risk of pathological fracture to the jaw. Erich arch bar splint was fixed over the lower arch to reinforce the weak jaw. Lower anterior teeth were planned to be treated with root canal therapy. Marsupialization through the labial vestibule was done to decompress the lesion

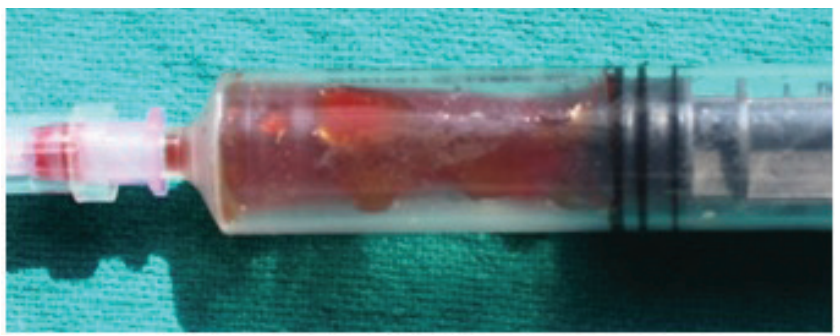

Figure 4: Positive aspiration from the lesion.

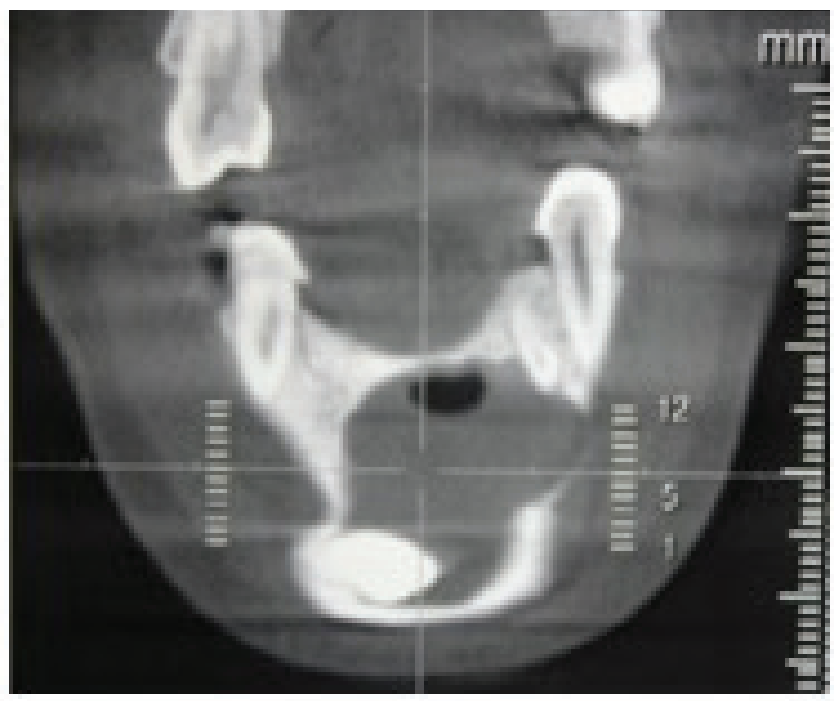

Figure 5: Computed tomography scan images showing large lesion and weakened jaw. 
under local anesthesia. The cyst cavity was packed with sterile iodoform gauze to achieve hemostasis and to prevent hematoma formation. Biopsy of lesion was sent for histopathological examination to confirm the initial diagnosis of dentigerous cyst (Figure 6A and $B$ ).

The iodoform gauze was changed on the third day. On follow-up examination, it was noticed that there was a significant movement of the impacted canine away from the lower border of the jaw and there was deposition of new bone, thus reducing the size of the cyst (Figure 7).

After 4 months of marsupialization, enucleation of the lesion was done along with the removal of the tooth (Figure 8). The whole lesion was sent for histopathological examination to confirm the initial diagnosis of dentigerous cyst and to rule out any ameloblastic changes in any portion of the lining (Figure 9).
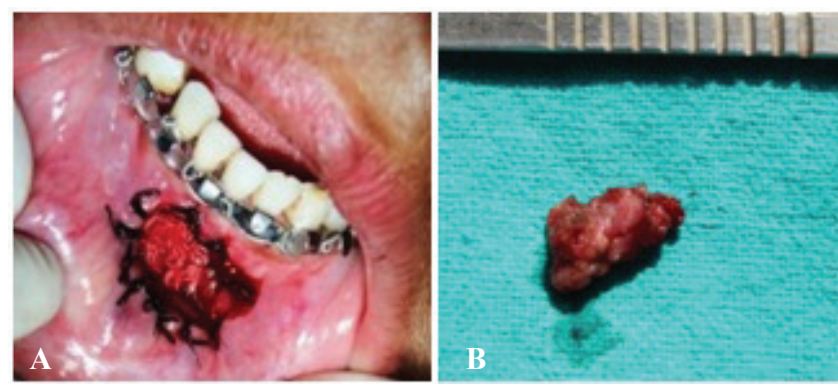

Figure 6: (A, B) Intraoperative images showing site of marsupialization. (A) Notice can be made of Erich arch bar splint to reinforce the weakened jaw, (B) enucleated lesion sent for histopathological examination.
The hematoxylin and eosin (H\&E)-stained section showed epithelium and connective tissue stroma. The cystic (epithelial) lining resembled reduced epithelium, showing cellular hyperplasia. Connective tissue stroma was dense and consisted of plump-shaped fibroblasts and numerous inflammatory cells chiefly lymphocytes. These features confirmed the initial diagnosis of inflammatory dentigerous cyst (Figure 10).

Six months after the second surgery, X-ray revealed normal calcification of the lesion site without any complaint from patient side and also the face appeared symmetrical without any abnormality (Figs. 11 and 12).
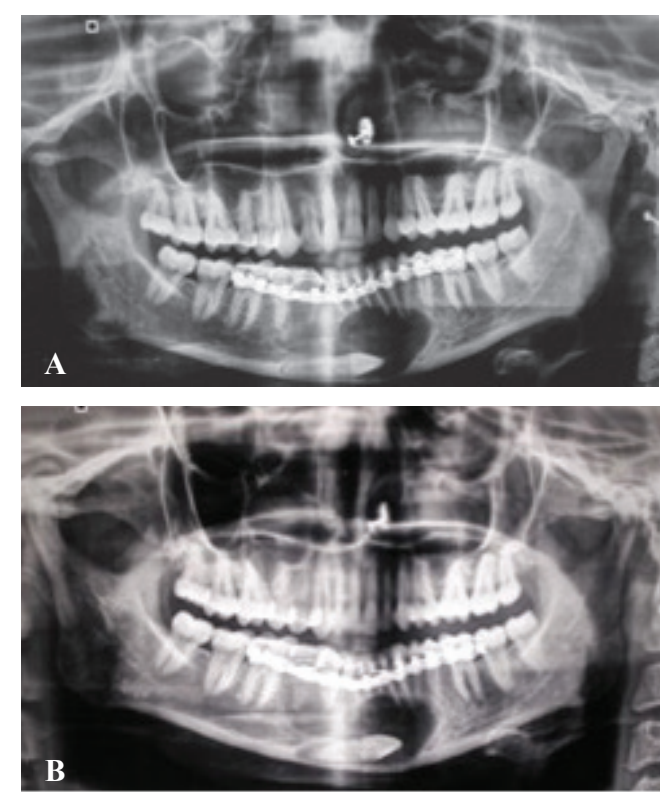

Figure 7: (A, B) OPG shows reduction in size of lesion and movement of impacted canine after 4 months of initial surgery.
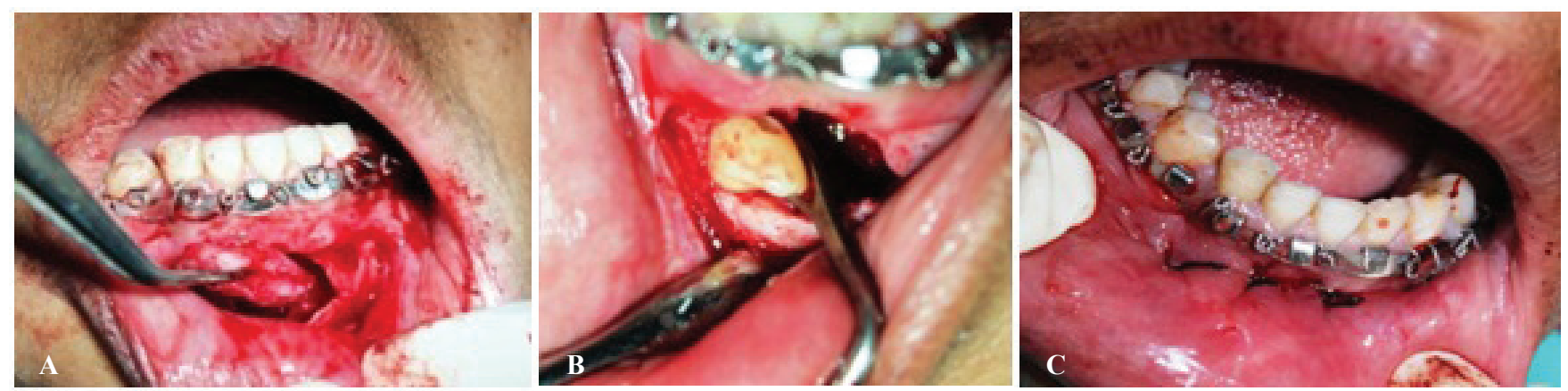

Figure 8: (A-C) Intraoperative images showing site of enucleation of lesion along with removal of canine. 


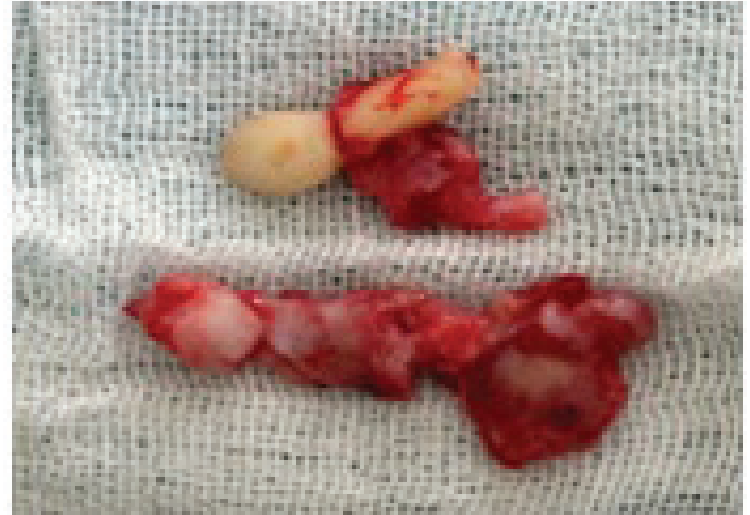

Figure 9: Excision of lesion along with tooth.
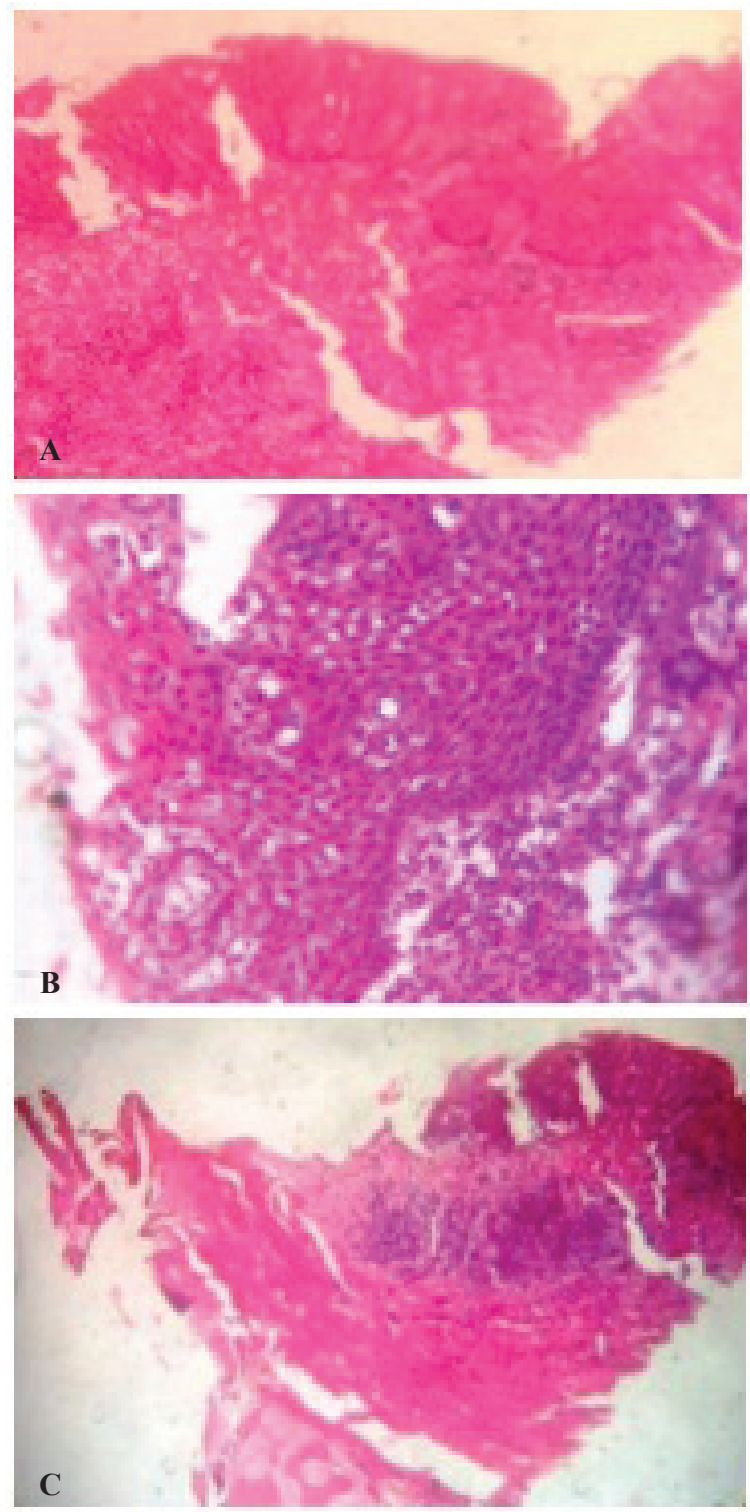

Figure 10: $(\mathrm{A}-\mathrm{C})$ Histopathological slides showing lining of the dentigerous cyst.

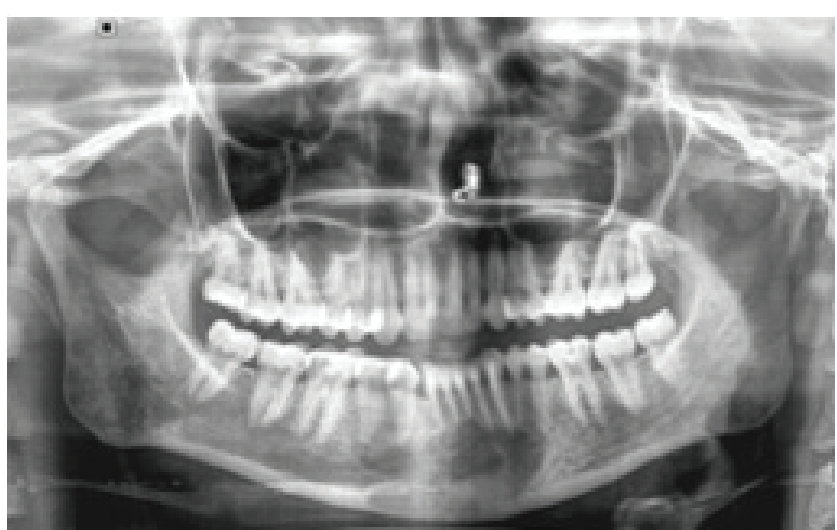

Figure 11: Six months postoperative OPG.

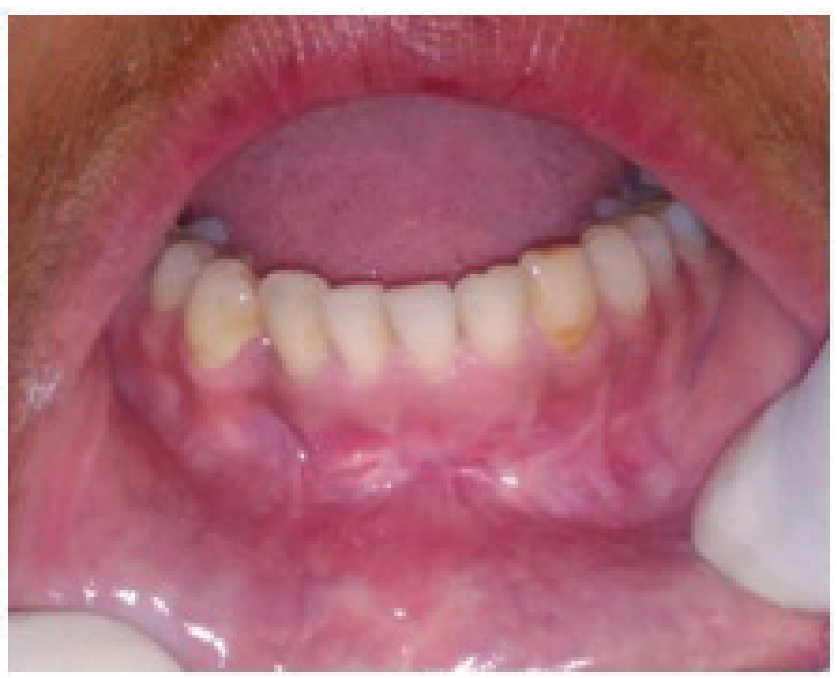

Figure 12: Six months postoperative intraoral image of the patient showing healed wound.

\section{CASE 2}

A 33-year-old female patient reported to the Department of Oral and Maxillofacial Surgery with a chief complaint of swelling on right side of the face which was enlarging slowly since last 1 year, leading to facial asymmetry (Figure 13). The patient gave a history of intermittent pain in upper teeth since more than a year, which used to subside on taking pain killers. There was no history of nasal discharge or blockage.

On general examination, the patient appeared healthy and there was no apparent history of past illness or hospitalization or trauma to the jaws.

On extraoral examination, facial asymmetry was noted on the middle third of the face, with no sinus or active discharge of pus. The submandibular lymph 


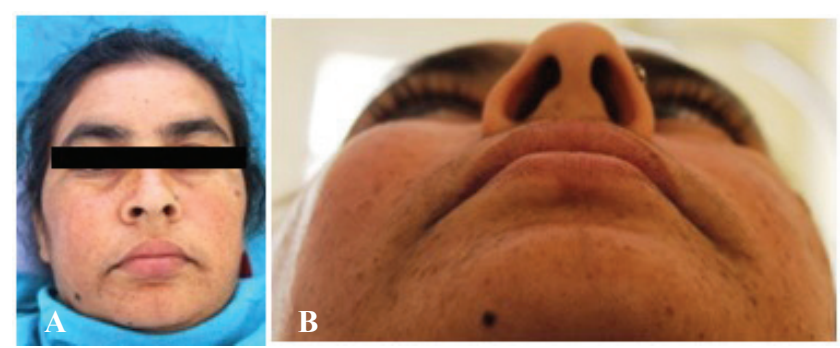

Figure 13: (A, B) Clinical image of the patient showing swelling over right middle third of face.

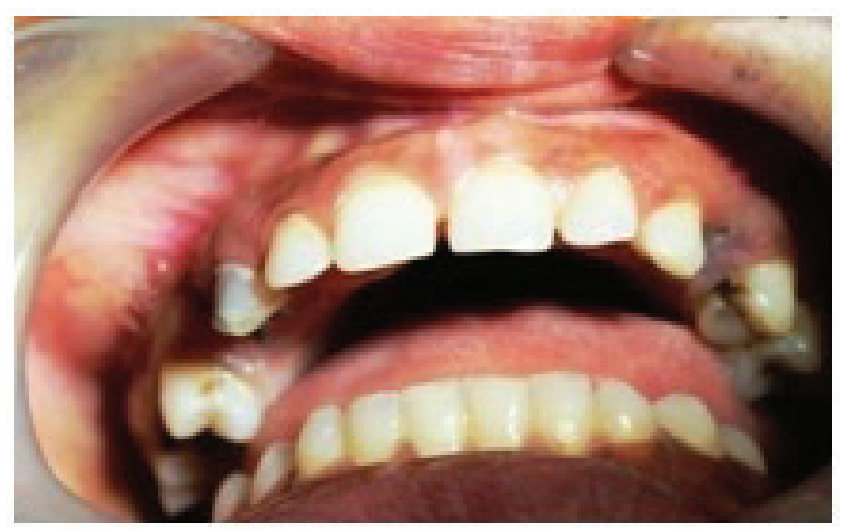

Figure 14: Intraoral image of the patient showing swelling in posterior teeth region obliterating buccal vestibule.

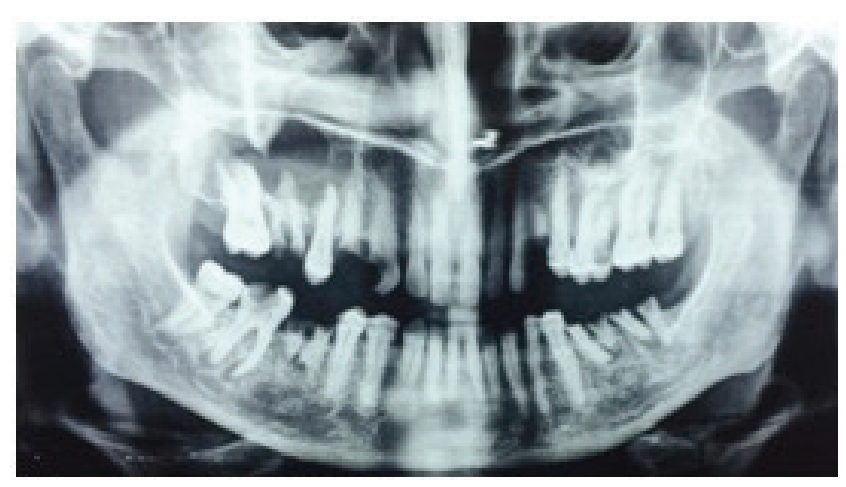

Figure 15: OPG showing large radiolucent lesion in relation to the molar premolar area on the right side of maxilla. nodes were nonpalpable. On intraoral examination, a firm swelling in maxillary posterior teeth region was noted with obliteration of the buccal vestibule (Figure 14). The consistency of the swelling was firm but could be compressed under finger pressure. No bone expansion was noted on the palatal side. There was no history of extraction of any tooth. Residual root stump of right upper first premolar was present and upper first molar and canine on right side were carious.

In the Orthopantomograph, radiolucent lesion was evident in relation to the molar premolar area which was partially obliterating the maxillary sinus (Figure 15).

The contents of the swelling were aspirated which revealed straw colored fluid. The cytopathologic examination of the aspirate showed mucoid material, $\mathrm{RBC}$, clumps of benign epithelial cells, and plenty of cyst macrophages.

A provisional diagnosis of radicular cyst was made on the basis of history, clinical, and radiological findings. Maxillary second premolar was found to be vital.

For better study of the extension of the lesion into the maxillary sinus, computed tomographic examination was done which revealed that more than two-thirds of the sinus were involved but the floor of the orbit was spared (Figure 16).

For the management of the case, a preventive approach was followed as there was a real risk of opening into the maxillary sinus and creating oroantral fistula. By extracting the involved first molar and widening the extraction socket marsupialization of the lesion was performed and portion of lining was sent for

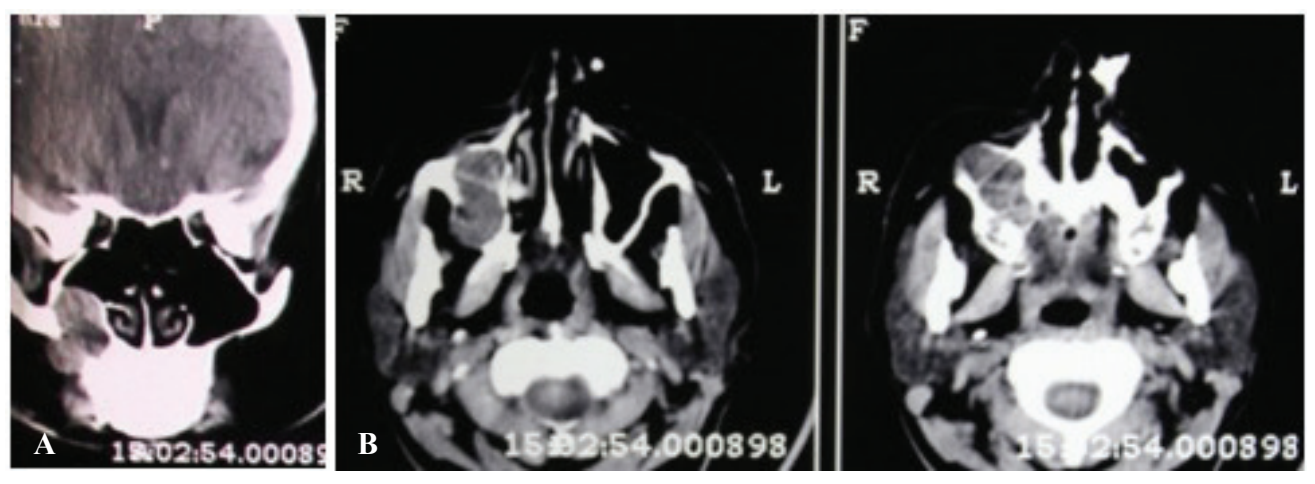

Figure 16: (A, B) Computed tomography scan images showing involvement of the maxillary sinus on right side. 

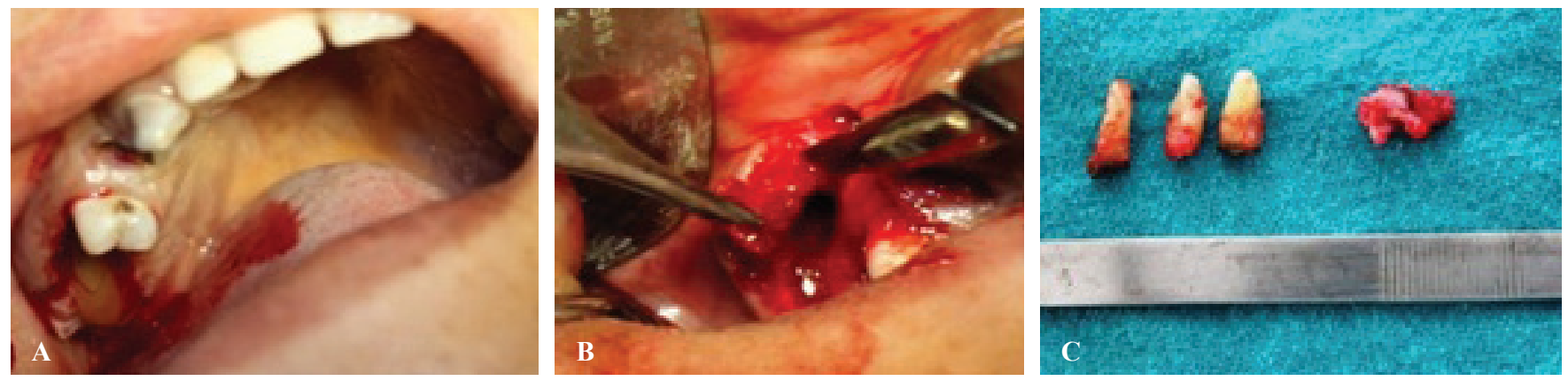

Figure 17: (A-C) Intraoperative images showing site of extraction of first molar roots along with marsupialization of lesion.
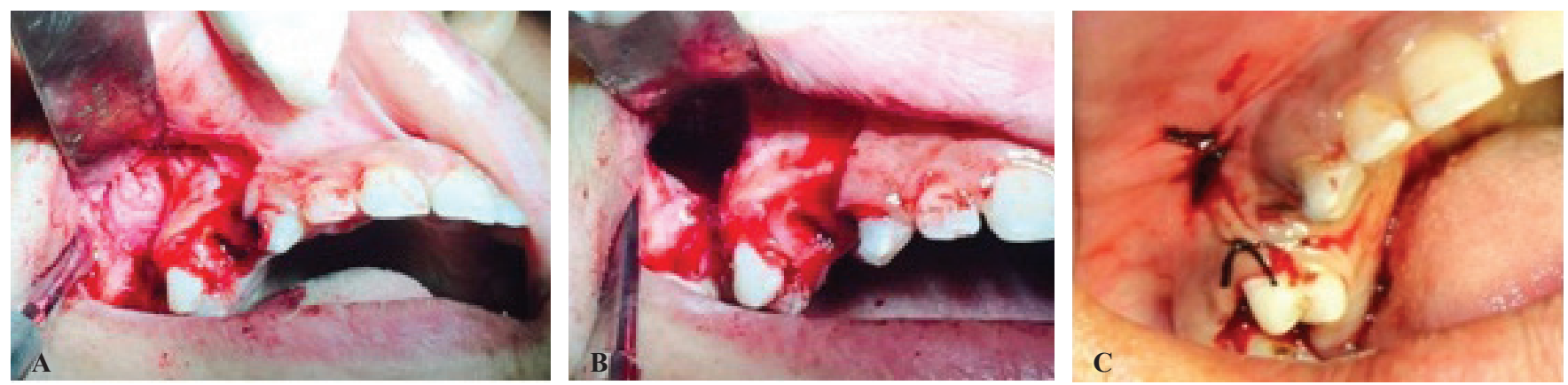

Figure 18: (A-C) Intraoperative images showing site of enucleation of lesion and closure of the opening.

histopathological examination (Figure 17). An acrylic obturator was fabricated to prevent the closure of the opening.

On follow-up, the size of the lesion was significantly reduced and the lesion was enucleated and primary closure of the opening was achieved without directly opening into the maxillary sinus. The whole lesion was sent for histopathological examination to confirm the initial diagnosis of radicular cyst (Figures 18 and 19).

The H\&E-stained section showed epithelium and connective tissue stroma. The epithelial lining was thin and regular, connective tissue comprised of numerous inflammatory cells chiefly lymphocytes. Few cholesterol crystals were also seen in the connective tissue stroma. These features confirmed the initial diagnosis of inflammatory radicular cyst (Figure 20).

Six months after the second surgery, X-ray revealed normal maxillary sinus without any complaint from patient side and also the face appeared symmetrical without any residual deformity (Figure 21).

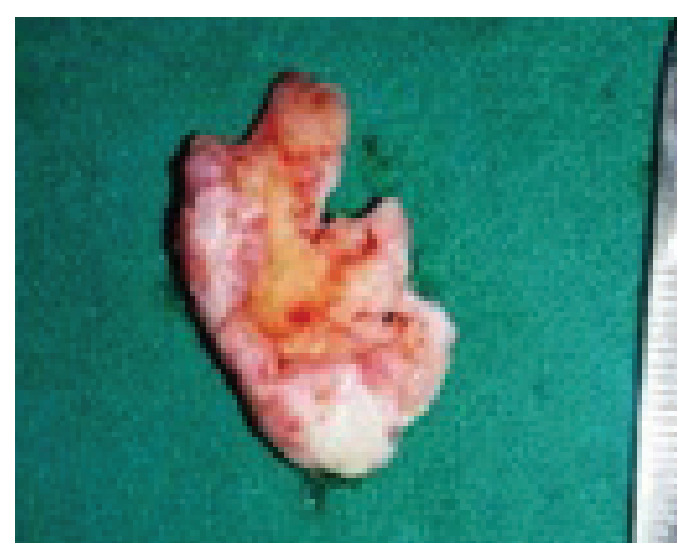

Figure 19: Enucleated lesion.

\section{DISCUSSION}

The dentigerous cyst is the second most common cyst of the jaws comprising 14 to $20 \%$, whereas the most common one, the radicular cyst, comprises $60 \%$ of all jaw cysts. Former are more frequent in males and more common in the mandible, whereas later may occur at any age and in any jaw. ${ }^{1-3}$ 

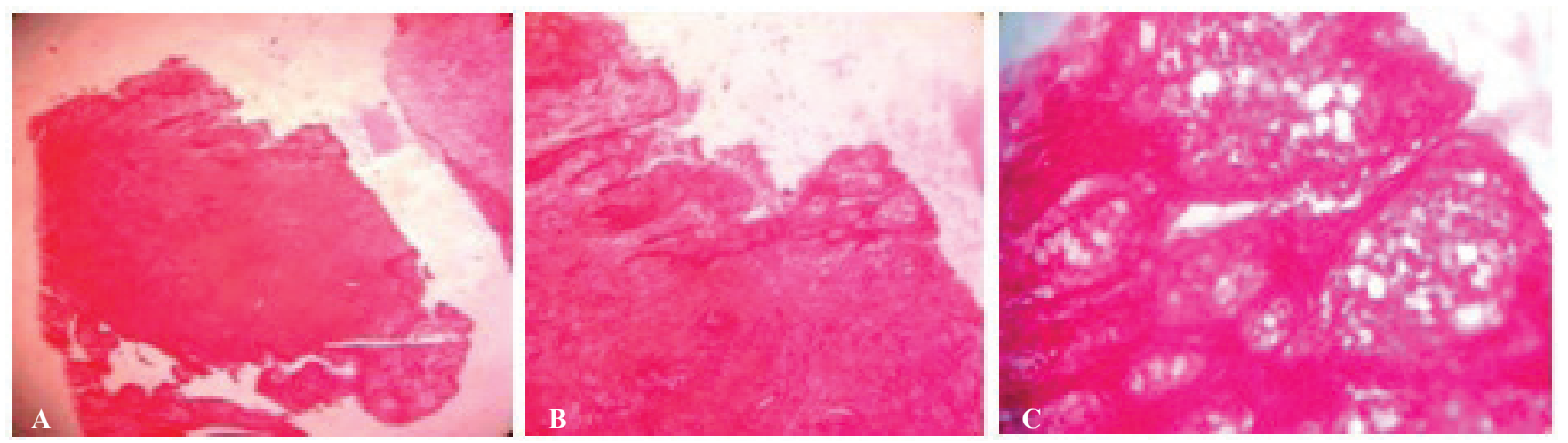

Figure 20: (A-C) Histopathological slides showing lining of the radicular cyst.
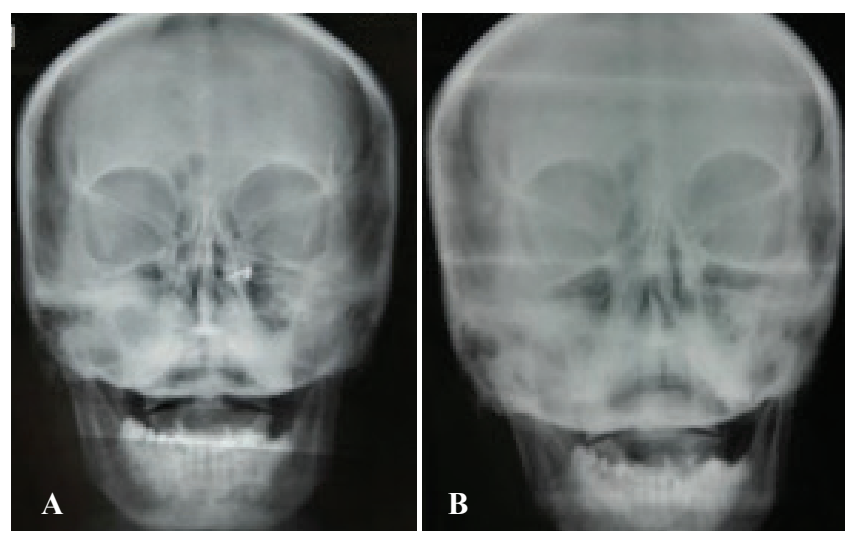

Figure 21: (A, B) Paranasal sinus views - preoperative and 6 months postoperative $\mathrm{X}$-rays.

Dentigerous cyst is attached to the cervix of an impacted tooth and results from proliferation of reduced enamel epithelium after the enamel formation. The dentigerous cyst is potentially capable of becoming an aggressive lesion. Expansion of the bone with subsequent facial asymmetry, extreme displacement of teeth, and root resorption of adjacent teeth and pain are all possible sequel brought about by continued enlargement of cyst. ${ }^{1-3}$

In our case, the right mandibular canine was missing and there was swelling over the lower jaw leading to facial asymmetry. A compressible painless bulge was present intraorally which on aspiration revealed strawcolored fluid indicating a cystic lesion. In second case, swelling was present on right maxillary region leading to facial asymmetry.

Dentigerous cysts are usually discovered on routine radiographic examination or when films are taken to determine the reason for failure of a tooth to erupt. They are radiolucent and usually unilocular, although large lesions occasionally show a scalloping or multilocular pattern. ${ }^{3-6}$

In our case, orthopantomograph showed a radiolucent lesion which had caused displacement of offending impacted canine to the lower border of the mandible and hollowing out the parasymphysis region. Computed tomography scan was advised which had revealed the real risk of pathological fracture.

Lower anterior teeth were found to be nonvital, while the premolars on the involved side were vital when tested for vitality.

In second case, Orthopantomograph showed a radiolucent lesion in relation to the molar premolar area which was partially obliterating the maxillary sinus. Computed tomographic examination revealed that more than two-thirds of the sinus were involved but the floor of the orbit was spared. ${ }^{7}$

Common methods of treatment are enucleation and marsupialization. In enucleation, whole of the lesion is removed leaving the defect to heal by primary bone formation. This is done when the lesion is small. In marsupialization, lesion is decompressed by creating a window in the wall of the lesion thus allowing the bone formation around the lesion and thereby reducing the size of lesion. This procedure is done in cases of larger cysts where there is risk of pathological fracture or damage to vital structures. ${ }^{1-3}$

In our case, a preventive approach was followed as there was a real risk of pathological fracture of the jaw. Erich arch bar splint was fixed over the lower arch 
to reinforce the weak jaw. Lower anterior teeth were root canal treated. Marsupialization through the labial vestibule was done to decompress the lesion under local anesthesia. The cyst cavity was packed with sterile iodoform gauze to achieve hemostasis and to prevent hematoma formation.

After 4 months of marsupialization, there was deposition of new bone, and reduction in the size of the cyst, so enucleation of the lesion was done along with the removal of the tooth (Figure 7).

It is of great clinical significance that numerous cases of ameloblastoma have been reported developing in the wall of dentigerous cyst from the lining epithelium or associated epithelial rests. So, all the tissues from the dentigerous cyst must undergo thorough gross and microscopic examination for any changes. ${ }^{8}$ In our case, histopathological examination confirmed the initial diagnosis of dentigerous cyst (Figure 10).

Six months after the second surgery, X-ray revealed normal calcification of the lesion site without any complaint from patient side and also the face appeared symmetrical without any abnormality (Figures 11 and 12).

In second case, again a conservative approach was followed as there was a real risk of opening into the maxillary sinus ${ }^{9}$ and creating oroantral fistula. By extracting the involved first molar and widening the extraction socket, marsupialization of the lesion was performed ${ }^{10}$ and enucleation was done after 6 months. An acrylic obturator was fabricated to prevent the closure of the opening in the interim period.

The whole lesion was sent for histopathological examination to confirm the initial diagnosis of inflammatory radicular cyst (Figure 19).

Six months after the second surgery, X-ray revealed normal maxillary sinus without any complaint from patient side and also the face appeared symmetrical without any residual deformity (Figure 21).

By following approach of marsupialization followed by enucleation, the potential risks of pathological fracture and creation of oroantral fistula ${ }^{11}$ were prevented in these cases.

Therefore, we can say there is definite advantage of marsupialization over enucleation in larger cysts and marsupialization is a reliable method of treatment of cyst.References

1. Shafer's textbook of Oral Pathology. Shafer, Hine, Levy, 7/e 2012; pp. 259, 260, 273.

2. Assael LA. Surgical management of odontogenic cysts and tumors. In Peterson L J, Indresano T A, Marciani R D, Roser S M. Principles of Oral and Maxillofacial Surgery. Philadelphia: JB Lippincott, 1992; Vol2: pp. 685-688.

3. Neville BW. Odontogenic cysts and tumors. In Neville B W, Damm D D, Allen C M, Bouquot J E. Oral and Maxillofacial Pathology. Philadelphia: WB Saunders, 1995; pp. 493-496.

4. Regezi JA. Cyst and cystlike lesions. InRegezi J A, Sciubba J, Pogrel M A. Atlas of Oral and Maxillofacial Pahtology. Philadelphia: WB Saunders, 2000; pp. 88.

5. Martínez-Pérez D, Varela-Morales M. Conservative treatment of dentigerous cysts in children: report of four cases. J Oral Maxillofac Surg 2001; 59: 331-334.

6. Dammer R, Niederdellmann H, Dammer P, et al. Conservative or radical treatment of keratocysts: A retrospective view. Br J Oral MaxillofacSurg 1997; 35: 46.

7. Schramm A, Rucker M, Sakkas N, et al. The use of cone beam CT in craniomaxilla facial surgery. Int Congress Series 2005; 1281:1200-4.

8. Shafer's textbook of Oral Pathology. Shafer, Hine, Levy, 6/ e2009; pp. 257.

9. Pekiner FZ, Borahan O, Ugurlu F, et al. Clinical and radiological features of a large radicular cyst involving the entire maxillary sinus. MUSBED 2012; 2:31-6.

10. Aguiló L, Gandía JL. Dentigerous cyst of mandibular second premolar in a five-year-old girl, related to a non vital primary molar removed one year earlier: A case report. J Clin Pediatr Dent1998; 22: 155.

11. Gibson GM. Case report: a large radicular cyst involving the entire maxillary sinus. Gen Dent 2002; 50:80-1. 